\title{
Changes in $5 \alpha$-Pregnane Steroids and Neurosteroidogenic Enzyme Expression in Fetal Sheep with Umbilicoplacental Embolization
}

\author{
PHUONG N. NGUYEN, SARAID S. BILLIARDS, DAVID W. WALKER, AND JONATHAN J. HIRST \\ Fetal and Neonatal Research Group, Department of Physiology, Monash University, Clayton, Victoria \\ 3800, Australia
}

\begin{abstract}
Pregnane steroids have sedative and neuroprotective effects on the brain, due to interactions with the steroid-binding site of the $\mathrm{GABA}_{\mathrm{A}}$ receptor. In the adult brain, synthesis of the pregnane steroids is increased in response to stress. Therefore, we have used umbilicoplacental embolization to mimic chronic placental insufficiency during late gestation in sheep, to investigate the expression of the steroidogenic enzymes P450scc, $5 \alpha$ reductase type I ( $5 \alpha \mathrm{RI}), 5 \alpha$-reductase type II ( $5 \alpha \mathrm{RII})$, and allopregnanolone (AP) content in the fetal brain. Umbilicoplacental embolization was induced from $114 \mathrm{~d}$ gestation (term $\sim 147 \mathrm{~d}$ ) by daily injection of inert microspheres into the umbilical artery and continued for 17-23 d. Fetal arterial oxygen saturation was reduced to $\sim 60 \%$ of the preembolization value in each fetus, with a significant reduction in blood arterial $\mathrm{Po}_{2}, \mathrm{pH}$, and plasma glucose concentrations $(p<0.05)$ and a significant increase in blood arterial $\mathrm{PCO}_{2}$ and plasma lactate concentrations $(p<0.05)$. At postmortem at 131-137 d gestation, embolized fetuses were growth-restricted $(2.10 \pm 0.14 \mathrm{~kg}, n=5)$ compared with agematched controls $(4.43 \pm 0.56 \mathrm{~kg}, n=7, p<0.05)$. Umbilicoplacental embolized fetuses showed increased P450scc expression in the primary motor cortex; $5 \alpha \mathrm{RI}$ expression was not
\end{abstract}

\section{ABSTRACT}

changed in any of the regions examined, whereas $5 \alpha$ RII expression was markedly increased in all brain regions. Brain AP content did not significantly change, whereas plasma concentrations were increased. These findings suggest that the increased expression of P450scc and $5 \alpha$ RII may be a response that maintains AP concentration in the fetal brain after compromised placental function and/or intrauterine stress. (Pediatr Res 54: 840-847, 2003)

\section{Abbreviations}

AP, allopregnanolone, $5 \alpha$-pregnan-3 $\alpha$-ol-20-one

P450sce, P450 side chain cleavage enzyme

$\mathbf{5} \boldsymbol{\alpha} \mathbf{R I}, 5 \alpha$-reductase type I enzyme

5 $\boldsymbol{\alpha R I I}, 5 \alpha$-reductase type II enzyme

PMC, primary motor cortex

$\mathbf{G A B A}_{\mathbf{A}}, \gamma$-aminobutyric acid/benzodiazepine

$\mathbf{5} \boldsymbol{\alpha}$-DHP, $5 \alpha$-dihydroprogesterone

$\mathrm{SaO}_{2}$, oxygen saturation of $\mathrm{Hb}$ in arterial blood

$\mathrm{PaCO}_{2}$, arterial $\mathrm{PCO}_{2}$

$\mathbf{P a O}_{2}$, arterial $\mathrm{PO}_{2}$

EMG, electromyogram
Chronic hypoxemia and placental insufficiency are associated with fetal growth retardation (1). Generally, the brains of these growth-retarded fetuses are either not smaller, or are reduced to a lesser degree compared with the overall size of the fetus, suggesting that the brain is able to adapt to the intrauterine conditions that compromise fetal growth. On the other hand, growth-retarded and premature infants are at a greater risk of perinatal brain damage (2), indicating that some of these adaptive changes leave the brain more vulnerable to cytotoxic

Received July 29, 2002; accepted May 26, 2003.

Correspondence: Jonathan Hirst, Department of Physiology, Monash University, Clayton Victoria 3800, Australia; e-mail: jon.hirst@med.monash.edu.au

Supported by a Monash University Faculty of Medicine Postgraduate Scholarship (P.N.N.), a National Health and Medical Research Council Dora Lush Postgraduate Scholarship (S.S.B.), and National Health and Medical Research Council of Australia Grant \#143503 (J.J.H., D.W.W.).

DOI: 10.1203/01.PDR.0000088066.47755.36 damage arising from a range of insults, such as acute hypoxia, asphyxia, or infection-induced inflammation.

Pregnane steroids, including AP, modify the excitability of the CNS by interaction with the $\mathrm{GABA}_{\mathrm{A}}$ receptor at the steroid binding site. In the adult, AP has been shown to have potent anxiolytic $(3,4)$, anticonvulsant $(5,6)$, sedative/hypnotic, and anesthetic effects (7) on behavior. A constitutive role for neuroactive steroids in the developing brain was proposed after the observation that progesterone metabolites such as AP appear to maintain the low level of arousal-like behavior that typifies fetal life $(8,9)$. In the rat, stressful stimuli of handling or swim stress have been shown to increase plasma AP content $(10,11)$, suggesting that modulation of the $\mathrm{GABA}_{\mathrm{A}}$ receptor by AP may limit CNS excitation in such circumstances. The presence of elevated concentrations of AP in the fetal brain may also prevent excessive excitation after periods of hypoxia or asphyxia. 
AP can be synthesized de novo from cholesterol in the brain, but a proportion may be derived from precursors in blood, including progesterone and pregnenolone that may enter the brain across the blood-brain barrier $(12,13)$. The cytochrome $\mathrm{P} 450$ side-chain cleavage enzyme (P450scc) catalyzes the conversion of cholesterol to pregnenolone on the inner surface of the mitochondrial membrane (14). The $5 \alpha$-reductase enzyme exists as two isoforms - type I and II — which both catalyze the conversion of progesterone to the $5 \alpha$-reduced derivative $5 \alpha$ DHP. The enzyme $3 \alpha$-hydroxysteroid dehydrogenase, which catalyzes the subsequent conversion of $5 \alpha$-DHP to AP, is also strongly expressed throughout the brain (15).

Hypoxemia resulting from chronic placental insufficiency has been shown to increase adrenal gland growth and function (16) and may provide a major source of metabolites that are subsequently converted to pregnane steroids in the brain. The aim of this study was to determine the effects of induced chronic placental insufficiency on the expression of the neurosteroid synthesizing enzymes, P450scc, $5 \alpha$-reductases I and II, and on the content of AP in various regions of the brain and adrenal glands.

\section{MATERIALS AND METHODS}

All procedures were conducted in accordance with the Code of Practice for the Care and Use of Animals for Scientific Purposes of the National Health and Medical Research Council and had received prior approval from the Monash University Standing Committee on Ethics in Animal Experimentation.

Animals. Surgery was performed on 12 pregnant Border Leicester/Merino crossbred ewes carrying a single fetus at $108-112 \mathrm{~d}$ gestation using aseptic techniques. General anesthesia was induced by i.v. injection of thiopentone sodium (20 $\mathrm{mg} / \mathrm{kg}$; Pentothal, Bomac Laboratories Ltd. Asquith, NSW, Australia) and maintained by inhalation of $1-2 \%$ halothane (Fluothane; ICI, Villawood, Australia) in $\mathrm{O}_{2}$. Polyvinyl catheters (outer diameter, $1.50 \mathrm{~mm}$; inner diameter, $1.00 \mathrm{~mm}$ ) were implanted into a femoral artery and femoral vein, with the tip of the femoral artery catheter advanced to the level of umbilical artery. An EMG electrode (Cooner Wire Co., Chatsworth, CA, U.S.A.) was fixed onto the uterus to monitor uterine electrical activity. The fetus was returned to the uterus, and the catheters and electrodes were exteriorized through a maternal flank incision. The ewe was allowed to recover for $2-3 \mathrm{~d}$ before beginning the experimental procedures.

Determination of blood gases, $\mathrm{pH}$, and glucose and lactate concentrations. Arterial blood gas parameters, $\mathrm{PaCO}_{2}, \mathrm{PaO}_{2}$, $\mathrm{SaO}_{2}$, and $\mathrm{pH}$ were determined using an ABL520 blood gas analyzer (Radiometer, Copenhagen Denmark). Fetal blood gas measurements were corrected to the expected fetal temperature of $39^{\circ} \mathrm{C}$. Blood glucose and lactate concentrations were measured by using a YSI 2300GL glucose and lactate analyzer (YSI Inc., Yellow Springs, OH, U.S.A.).

Umbilicoplacental embolization. At $114 \mathrm{~d}$ of gestation, fetal hypoxemia was induced by partial embolization of the umbilicoplacental circulation in five fetuses from singleton pregnancies as described previously (17). Briefly, unlabelled mucopolysaccharide microspheres (Sephadex G25, superfine, diameter
40-70 $\mu \mathrm{M}$, Pharmacia, Uppsala, Sweden) suspended in sterile heparinized saline containing $0.02 \%$ Tween 80 were injected into the fetal femoral catheter to induce umbilicoplacental embolization. Repeated injections of microspheres $(0.1-0.2$ million) were given every $10-20$ min until a fall in $\mathrm{SaO}_{2}$ occurred. After the initial fall in $\mathrm{SaO}_{2}$, hourly injections of microspheres were given until $\mathrm{SaO}_{2}$ reached the desired level of $20-30 \%$ (approximately $60 \%$ reduction of normal levels). After the onset of embolization, no further microspheres were given if the $\mathrm{SaO}_{2}$ was $<30 \%$. This treatment was performed daily until postmortem. EMG activity was continuously monitored in all ewes as the number of EMG burst recorded for each $2 \mathrm{~h}$ interval as previously described (18). Ewes were killed when there was an indication of the approach of labor onset based on a rise in EMG burst frequency that reached twice the basal frequency recorded between 114 and $125 \mathrm{~d}$ of gestation. Thus, all ewes with embolized fetuses were killed between 131 and $137 \mathrm{~d}$ of gestation before there was a change to the contracture pattern of EMG activity that is associated with the onset of active labor. Seven additional fetuses from singleton pregnancies received a daily injection of saline, were killed at 132-134 d gestation, and were used to provide control samples.

Tissue collection. Ewes and fetuses were killed by injection of an overdose of sodium pentobarbitone $(130 \mathrm{mg} / \mathrm{kg}$ i.v.) given to the ewe. The brains of the fetuses were immediately removed and divided into blocks corresponding to the following regions: cerebellum; hippocampus; medulla; midbrain; pons; hypothalamus/thalamus; and primary motor (PMC), frontal, parietal, occipital, and temporal cortex. Fetal adrenal glands were also collected. All tissue was frozen in liquid nitrogen and stored at $-70^{\circ} \mathrm{C}$.

$5 \boldsymbol{\alpha} \boldsymbol{R I}$ antisera. A polyclonal antipeptide antibody against a synthetic peptide corresponding to amino acids 234-249 of the enzyme deduced from the cDNA sequence (19) was prepared in three New Zealand White rabbits following standard protocols (20). The peptide was synthesized as previously described (21) and with a 94\% purity assessed by ion spray mass spectrometry. Rabbits were immunized and serum collected as previously described using standard protocols (20). Specificity of the antibody was assessed by immunoblotting and ELISA (22). The antisera raised against $5 \alpha \mathrm{RI}$ showed no crossreactivity with $5 \alpha \mathrm{RII}$ and showed a band at $23 \mathrm{kD}$ (the expected size of human $5 \alpha \mathrm{RI}$ ). Preimmune sera did not show any bands, and no bands were observed on immunoblots when antisera were preabsorbed with $15 \mu \mathrm{g}$ of antigen.

Immunoblotting. Cytochrome P450scc, $5 \alpha \mathrm{RII}$, and $5 \alpha \mathrm{RI}$ expression in the brain and adrenal glands was determined by Western immunoblotting. Immunoblotting was performed as previously described (21). Briefly, frozen samples $(\sim 0.1 \mathrm{~g})$ from each brain or adrenal glands were homogenized and then concentrated by ammonium sulfate precipitation. Protein content was determined in an aliquot according to the method of Bradford (23) using BSA as a standard. Fifteen micrograms protein was separated by SDS-PAGE on $15 \%$ separating gel and transferred onto $0.2 \mu \mathrm{M}$ polyvinylidene difluoride membranes (Osmonics, Westborough, MA, U.S.A.) by electroblotting. Membranes were blocked for $1 \mathrm{~h}$ at $22^{\circ} \mathrm{C}$ in TBST $(25$ 
$\mathrm{mM}$ Tris, $14 \mathrm{mM}$ sodium chloride, $0.2 \%$ (vol/vol) Tween-20, $\mathrm{pH}$ 7.4) containing $5 \%(\mathrm{wt} / \mathrm{vol})$ skim milk powder and incubated with a 1:3000 dilution of either the P450scc, $5 \alpha \mathrm{RI}$, or $5 \alpha$ RII antibody in TBST, for $1 \mathrm{~h}$ at $22^{\circ} \mathrm{C}$. Specificity of the $\mathrm{P} 450 \mathrm{scc}$ and $5 \alpha \mathrm{RII}$ antibodies have been previously reported (21). The membranes were washed with TBST, followed by 1:3000 dilution of a horse radish peroxidase-conjugated goat anti-rabbit IgG (DAKO, Glostrup, Denmark) for $30 \mathrm{~min}$, followed by washes in TBST. The immune complexes were visualized by chemiluminescence using the Amersham ECL detection system (Amersham, Buckinghamshire, UK) for 1 min and captured using BioMax ML autoradiograph film (Eastman Kodak, Rochester, NY, U.S.A.). The autoradiographs were scanned and the images were imported into ImageQuaNT (Amersham). The intensities of the bands were quantified using ImageQuaNT and were individually corrected for background by subtracting the density of the blank background area immediately below each band.

Neurosteroid RIA. Neurosteroids were extracted from brain or adrenal tissue and plasma by a modification of the method of Barbaccia et al. (24) as previously described (21). Briefly, brain or adrenal gland tissue were homogenized three times with $50 \%$ methanol containing $1 \%$ acetic acid and the supernatants pooled. The supernatant was then applied to preprimed Sep-Pak C18 cartridges (Waters, Milford, MA, U.S.A.) and steroids were eluted with $100 \%$ methanol and the collected fractions dried under $\mathrm{N}_{2}$, and the steroids resuspended in 1.0 $\mathrm{mL}$ assay buffer (0.1 M PBS, $\mathrm{pH} 7.0)$. The recovery of steroids was monitored by adding radiolabeled steroid (5000 c.p.m) to two homogenates run in parallel with each extraction run. The recovery for the progesterone extraction was $86.5 \% \pm 4.5 \%(n$ $=3$ extractions) and for the pregnenolone extraction was $57.8 \% \pm 4.1 \%$ ( $n=3$ extractions), respectively, and corrections for losses during extraction were included in final calculations.

AP was measured by specific RIA, as previously described (21) using a polyclonal antibody purchased from Dr. R. H. Purdy (Department of Psychiatry, Veterans Administration Hospital, San Diego, CA, U.S.A.), which has been previously characterized (25). The limit of detection for AP was $0.19 \pm$ $0.03 \mathrm{pmol} /$ tube $(n=3)$ and the intra- and interassay coefficients of variance were $5 \%$ and $9 \%$, respectively. Pregnenolone and progesterone were measured by specific RIA using antibodies purchased from ICN Biomedicals (Seven Hills, NSW, Australia) and provided by Dr. J. Malecki (Bairnsdale, Victoria, Australia), respectively, as previously described (26). The limit of detection for pregnenolone was $0.09 \pm 0.02 \mathrm{pmol} / \mathrm{tube}$ $(n=3)$ and progesterone was $0.12 \pm 0.02 \mathrm{pmol} /$ tube $(n=3)$. The intra- and interassay coefficients of variance were $5 \%$ and
$16 \%$, respectively, for pregnenolone and $8 \%$ and $19 \%$, respectively, for progesterone.

Cortisol RIA. Cortisol was extracted from plasma with dichloromethane and was measured by RIA as previously described (27). Intra- and interassay coefficients were $4 \%$ and $15 \%$, respectively. The sensitivity of the assay was $0.33 \mathrm{pmol} /$ tube $(n=2)$.

Statistical analysis. Data are shown as mean \pm SEM. All data were analyzed using statistical software (SPSS Version 9.0, SPSS Inc., Chicago, IL, U.S.A.). Significance of changes in brain neurosteroidogenic enzyme content was determined by $t$ test. The Holm's step-down modification of Bonferroni's correction for multiple comparisons was used to avoid the potential for the introduction of type-I errors (28). Changes in brain neurosteroid content were examined using two-way ANOVA with treatment and brain region the factors in the analysis. Changes in fetal blood parameters, glucose and lactate, were examined using two-way ANOVA for repeated measurements. Differences between individual means were determined using by Fisher's least significant difference posthoc test. Adrenal steroid content and plasma steroid concentrations values were compared using $t$ test. A $p$ value $<0.05$ was considered to be statistically significant.

\section{RESULTS}

Fetal body and brain weights. The gestational age at postmortem examination was $132-134 \mathrm{~d}$ in control fetuses and 131-137 d in umbilicoplacental embolized fetuses. All fetuses were obtained before there was a change in uterine EMG activity from the gestational-associated contracture pattern and, thus, before the onset of active labor. Embolization resulted in a significant reduction in body weight (embolization, $2.10 \pm 0.14 \mathrm{~kg}, n=5$, versus control, $4.43 \pm 0.56 \mathrm{~kg}, n=7$; $p<0.05$ ), but there was no change in brain weight (embolization, $37.59 \pm 1.84 \mathrm{~g}, n=5$, versus control, $40.05 \pm 2.35 \mathrm{~g}$, $n=7)$.

Fetal blood gases analysis. Placental embolization for $17-23 \mathrm{~d}$ resulted in a significant reduction in fetal $\mathrm{SaO}_{2}, \mathrm{PaO}_{2}$, and $\mathrm{pH}$ (Table 1). Mean arterial glucose concentrations were significantly lower in the embolized fetuses whereas $\mathrm{PaCO}_{2}$ and lactate concentrations were significantly increased (Table 1). The total number of spheres delivered to the fetuses to maintain the desired level of hypoxemia ranged from 0.1 to 2 million per day with the total number of spheres administered to each fetus over the study period ranged from 1.25 to 6.45 million.

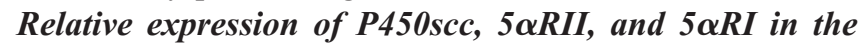
different brain regions. The relative abundance of $\mathrm{P} 450 \mathrm{scc}$, $5 \alpha \mathrm{RII}$, and $5 \alpha \mathrm{RI}$ expression in the different brain regions was

Table 1. Arterial blood measurements in the control and umbilicoplacental embolized fetuses

\begin{tabular}{|c|c|c|c|c|c|c|c|}
\hline & $\mathrm{pH}$ & $\mathrm{PCO}_{2}(\mathrm{mmHg})$ & $\mathrm{Po}_{2}(\mathrm{mmHg})$ & $\begin{array}{c}\mathrm{HCO}_{3^{-}} \\
(\mathrm{mmol} / \mathrm{L})\end{array}$ & $\mathrm{SaO}_{2}(\%)$ & $\begin{array}{l}\text { Lactate } \\
(\mathrm{mmol} / \mathrm{L})\end{array}$ & $\begin{array}{l}\text { Glucose } \\
(\mathrm{mmol} / \mathrm{L})\end{array}$ \\
\hline Control $(n=7)$ & $7.35 \pm 0.01$ & $45.33 \pm 1.17$ & $21.42 \pm 0.63$ & $24.02 \pm 0.79$ & $64.88 \pm 2.08$ & $0.68 \pm 0.07$ & $0.74 \pm 0.06$ \\
\hline IUGR $(n=5)$ & $7.31 \pm 0.01 *$ & $53.49 \pm 0.49^{*}$ & $11.12 \pm 0.21 *$ & $25.57 \pm 0.30$ & $19.22 \pm 0.76^{*}$ & $1.73 \pm 0.26^{*}$ & $0.42 \pm 0.05^{*}$ \\
\hline
\end{tabular}

Values shown are $\mathrm{PaCO}_{2}, \mathrm{PaO}_{2}, \mathrm{SaO}_{2}, \mathrm{pH}$, plasma glucose, and lactate concentrations at the time of tissue collection. Umbilicoplacental embolized fetuses were hypoxemic and hypoglycemic. Data presented as mean \pm SEM. Asterisks indicate significant differences between control and embolized fetuses $(p<0.05)$. 
assessed with two age-matched fetuses, a control and a umbilicoplacental embolized fetus at $134 \mathrm{~d}$ gestation (Fig. 1). As shown in Figure 1, all regions in either the control or embolized fetus were examined on individual blots. In both the umbilicoplacental embolized fetus and control fetus, the highest relative expression of P450scc and $5 \alpha$ RII occurred in the medulla, midbrain, and pons (Fig. 1, lanes 3, 4, 5). $5 \alpha$ RI was detected throughout the brain at relatively low levels, however, no differences between brain regions in the relative expression of $5 \alpha$ RI were apparent (data not shown).

Effect of placental embolization on the expression of

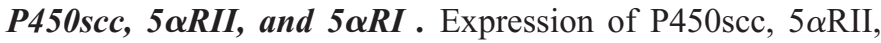
and $5 \alpha \mathrm{RI}$ in the cerebellum, hippocampus, medulla, hypothalamus/thalamus, and PMC were compared directly between the control and umbilicoplacental embolized fetuses on individual immunoblots for each area as described previously (21), and densitometry was then used to compare between all of the control and embolized fetuses. P450scc expression was significantly increased in the PMC of the embolized fetuses compared with controls, with no differences in expression in the other regions examined $(p<0.05$; Fig. $2 A)$. There was no change in $5 \alpha \mathrm{RI}$ expression in the embolized fetal brain, although there was a trend toward higher expression in the hypothalamus/thalamus (Fig. $2 B$ ). In contrast, $5 \alpha$ RII expression was significantly increased after embolization in all the brain regions examined ( $p<0.05$; Fig. $2 C)$.

Brain and adrenal steroid content. Whereas both AP and progesterone content appeared lower in most region of the brain after embolization, there were no significant changes in AP content (Fig. 3A). Progesterone content was significantly reduced in the hypothalamus/thalamus of embolized fetuses, but not in the other regions examined (Fig. $3 B$ ). There were also no significant between-region differences in AP and progesterone content in either the control or embolized fetuses. There were no differences in pregnenolone content in any of the brain regions examined between control and embolized groups of fetuses, although content appeared more variable in

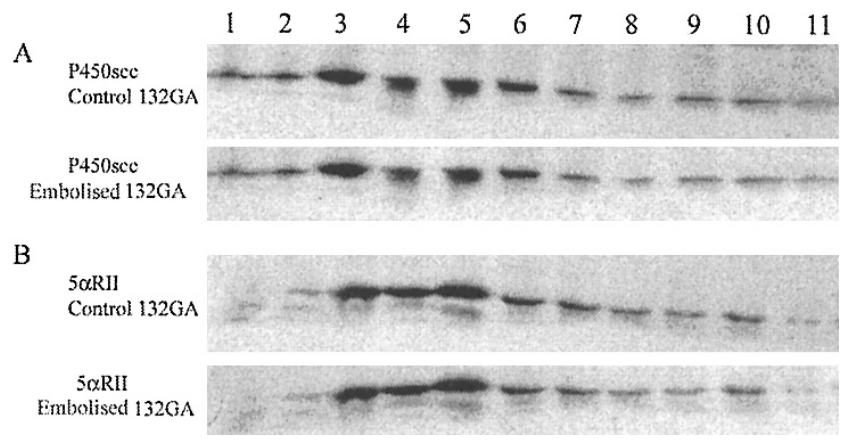

Figure 1. Expression of $(A) \mathrm{P} 450 \mathrm{scc}$ and $(B) 5 \alpha \mathrm{RII}$ in brains of a control fetus at $134 \mathrm{~d}$ gestation and a umbilicoplacental embolized fetus at $134 \mathrm{~d}$ gestation. Lanes marks indicate the following regions; 1: cerebellum, 2: hippocampus, 3 : medulla, 4: midbrain, 5: pons, 6: hypothalamus/thalamus, 7: PMC, 8: frontal cortex, 9: occipital cortex, 10: parietal cortex, and 11: temperol cortex. Protein $(15 \mu \mathrm{g})$ was separated on $10 \%$ polyacrylamide gels, transferred to PVDF membranes, and incubated with either P450scc or $5 \alpha$ RII antisera. Expression of both P450sec and $5 \alpha$ RII was found to be highest in the brain stem (medulla and pons) and midbrain in both the control and umbilicoplacental embolized fetus. the embolized group (Fig. 3C). Pregnenolone and progesterone content was significantly increased in the adrenal gland of the embolized fetuses (Fig. 4, $B$ and $C$ ); the trend toward increased AP in these fetuses did not reach significance $(p=0.069)$.

Plasma steroid concentrations. Plasma AP and cortisol concentrations were significantly higher after embolization compared with control fetuses (Fig. 5, $A$ and $B$ ). However, plasma pregnenolone and progesterone concentrations were not different in the two groups of fetuses (Fig. 5, $C$ and $D$ ).

\section{DISCUSSION}

The principal finding of this study was that chronic embolization of part of the fetal side of the placenta resulted in elevated expression of P450sce in the primary motor cortex and $5 \alpha$ RII in all regions of the fetal brain examined. In this study, we used a previously established technique of umbilicoplacental embolization $(1,17)$ to induce changes in fetal blood parameters and fetal weight that was consistent with a severe and chronic reduction of placental function. We found that significant fetal hypoxemia, acidosis, and hypoglycemia was maintained during the embolization period, whereas plasma lactate concentrations were increased. Consistent with previous studies, this treatment reduced fetal body weight but not brain weight $(29,30)$. These findings show that this method mimics the changes in fetal growth associated with chronic placental insufficiency (1).

The present study examined the expression of two key rate-limiting steroidogenic enzymes, P450scc and $5 \alpha$ RII, in the steroidogenic pathway that leads to AP production in the brain. P450scc is responsible for the production of pregnenolone, the obligate precursor for neuroactive steroid production, and $5 \alpha \mathrm{RII}$ catalyzes the synthesis of $5 \alpha$-DHP, the immediate precursor for AP synthesis. The finding that both enzymes are strongly expressed in fetal brain in late gestation, with marked regional differences in the level of expression between regions, is consistent with our previous studies and supports the contention that AP may be synthesized de novo from cholesterol in the fetal brain $(21,31)$.

The finding that P450scc content in the brain was significantly increased in the PMC, showed a trend toward higher expression in the hippocampus, but was unchanged in the other regions examined suggests the mechanisms by which embolization affects the expression of this enzyme differs markedly between regions. The mechanisms that control the expression of the CYP11A1 gene, which encodes P450scc in the brain, are unclear. These mechanisms have been shown to be independent of SF-1 (steroidogenic factor 1), the transcription factor that regulates $\mathrm{P} 450 \mathrm{scc}$ expression in the adrenal glands. These observations indicate that the region-specific control of P450scc expression in the brain differs from the adrenal glands, however, the nature of this regulation awaits further investigation.

The finding that $5 \alpha$ RII content was markedly increased in all regions of the brain after umbilicoplacental embolization suggests similar regulatory pathways may be activated throughout the brain. Although the mechanisms that control of $5 \alpha$ RII expression in the brain also remains uncertain. Analysis of the 
Cerebellum

A
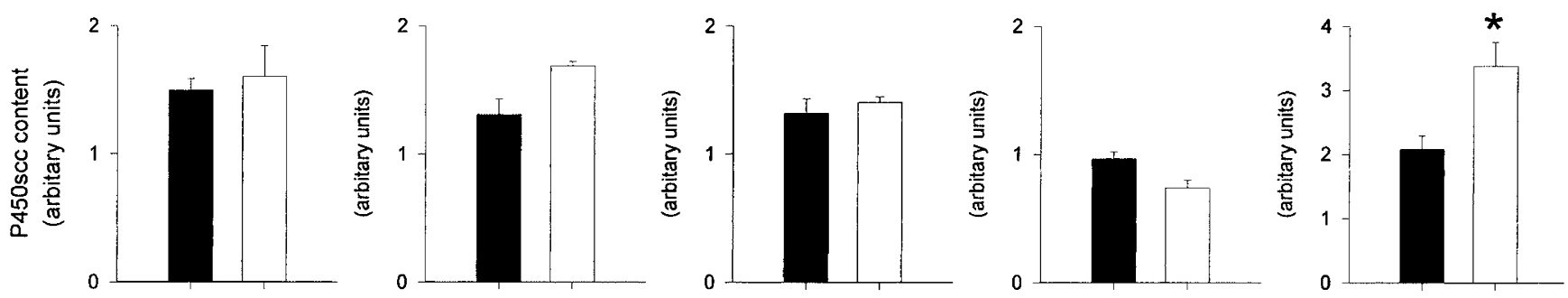

B
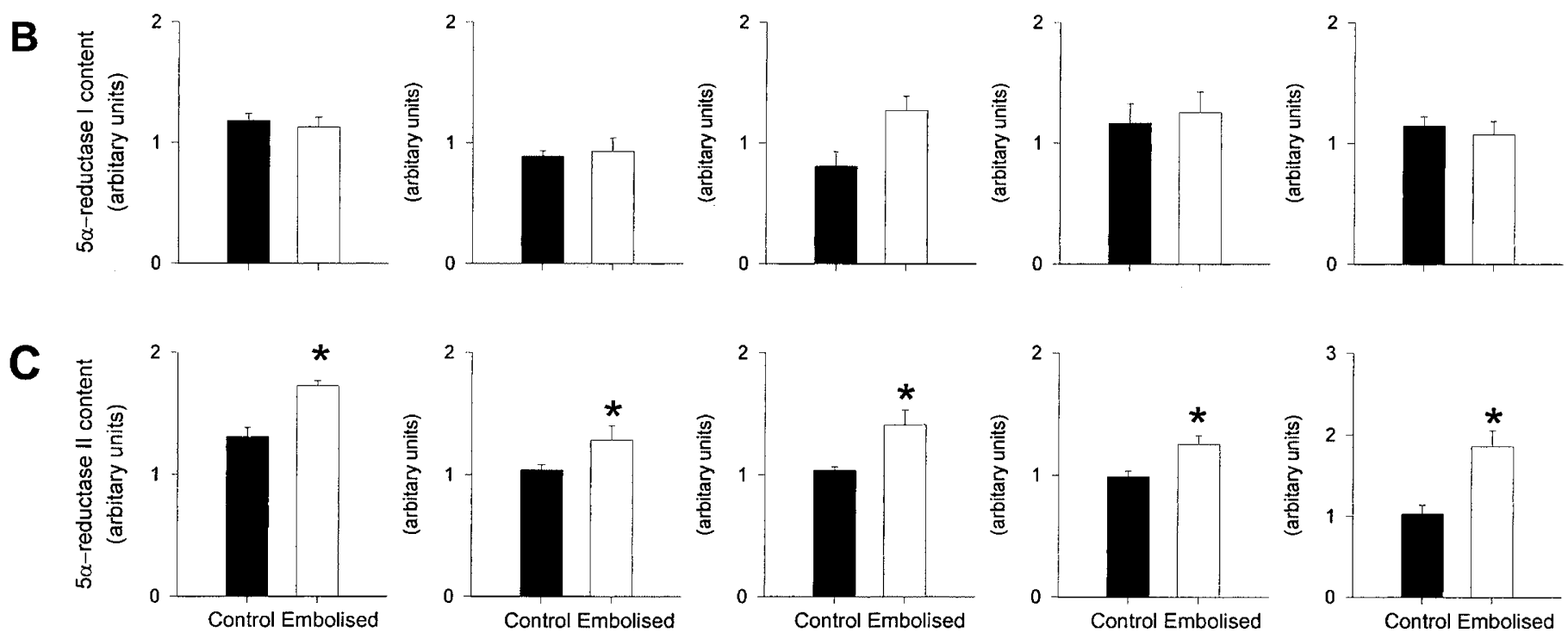

Figure 2. Densitometry values of $(A) \mathrm{P} 450 \mathrm{scc},(B) 5 \alpha \mathrm{RI}$, and (C) $5 \alpha \mathrm{RII}$ expression in the cerebellum, hippocampus, hypothalamus/thalamus, medulla, and PMC of control fetuses at $132-134 \mathrm{~d}$ gestation ( $n=7$, filled columns) and umbilicoplacental embolized fetuses $(n=5$, open columns) at $131-137 \mathrm{~d}$ gestation. Each bar represents the mean \pm SEM of expression in arbitrary units. Asterisks indicate significant differences between control and embolized fetuses $(p<0.05)$.

$5 \alpha$ RII gene in the mouse brain indicates the presence of a progesterone regulatory element (32). However, although this suggests that this steroid may have a direct role in the regulation of $5 \alpha$ RII enzyme expression, the results of the present study are not consistent with such a mechanism because $5 \alpha$ RII expression was increased throughout the brain after embolization, despite pregnenolone and progesterone concentrations either remaining unchanged or decreasing.

Previous studies using this model of placental insufficiency from mid-gestation to near term in sheep have shown a number of effects on the fetal brain, such as selective neuronal loss and cerebral infarction $(29,30,33)$. Studies have found that a 12 -h episode of placental underperfusion in the fetal sheep at midgestation results in the mild focal damage in the cortical white matter and a reduction in the number of cerebellar Purkinje neurons, the width of the molecular layer, and the area of the inner granule cell layer (33). Shorter periods of hypoxemia (8 h) result in predominately white matter injury with some adjacent cortical necrosis but no selective neuronal injury (34). In the growth-retarded guinea pig and rat, myelination was found to be both reduced and retarded by chronic hypoxemia $(35,36)$. Together, these findings indicate that a severe and chronic reduction in placental function results in a major alteration in the composition of cell types and myelination in many areas of the brain. These changes may result in a compensatory mechanism(s) that could account for the differences in steroidogenic enzyme expression after embolization and neurosteroid content in particular regions of the brain.

Despite the increase in $5 \alpha$ RII expression observed in all regions of the brain examined, AP concentrations did not change significantly and, if anything, tended to be lower after embolization. This may be the result of the lower progesterone concentrations after placental embolization and a consequently reduced progesterone precursor availability for AP synthesis. Our previous studies suggest that high brain AP concentrations during gestation are dependent on a supply of placental precursors, possibly progesterone, inasmuch as AP concentrations decline sharply after removal of the placenta at birth (21). In addition, a reduction in placental function may decrease the concentrations of other possible precursors for AP production such as the progesterone metabolite $3 \alpha$-hydroxyprogesterone that is present in the fetal circulation (37). Importantly, the observed increase in enzyme content that was observed in the present study may not necessarily translate to active enzyme in vivo. Therefore, it is possible that other unknown factor(s) resulting from embolization may reduce enzyme activity and suppress AP production. The observed increase in $5 \alpha$ RII expression may serve to maintain AP production to preserve 
A

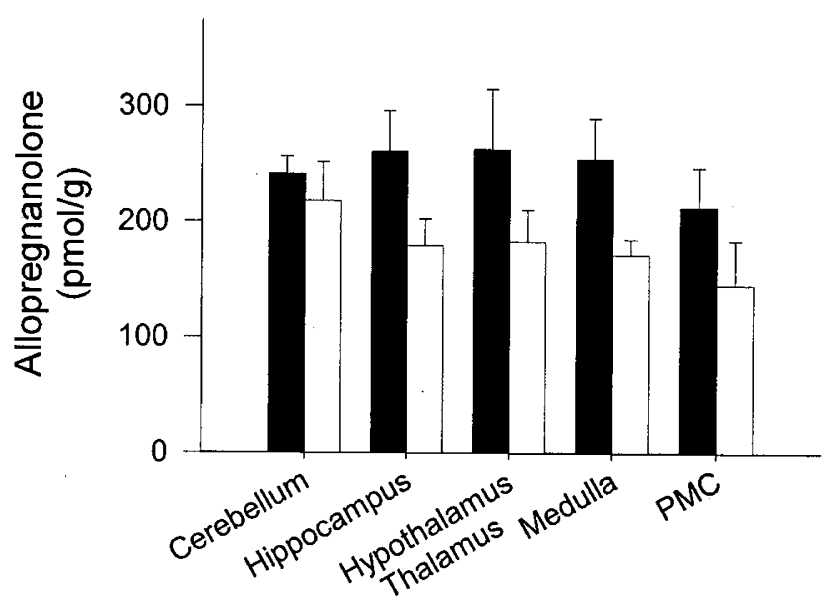

B

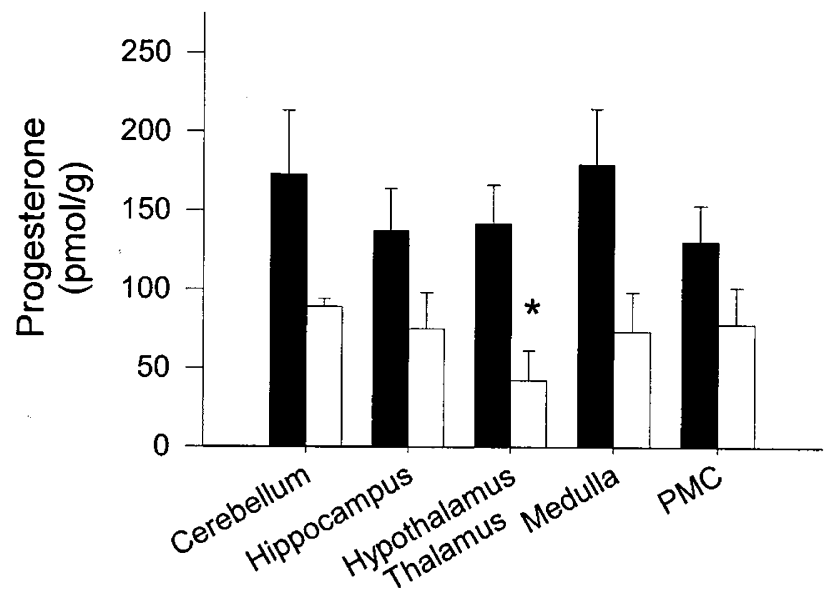

C

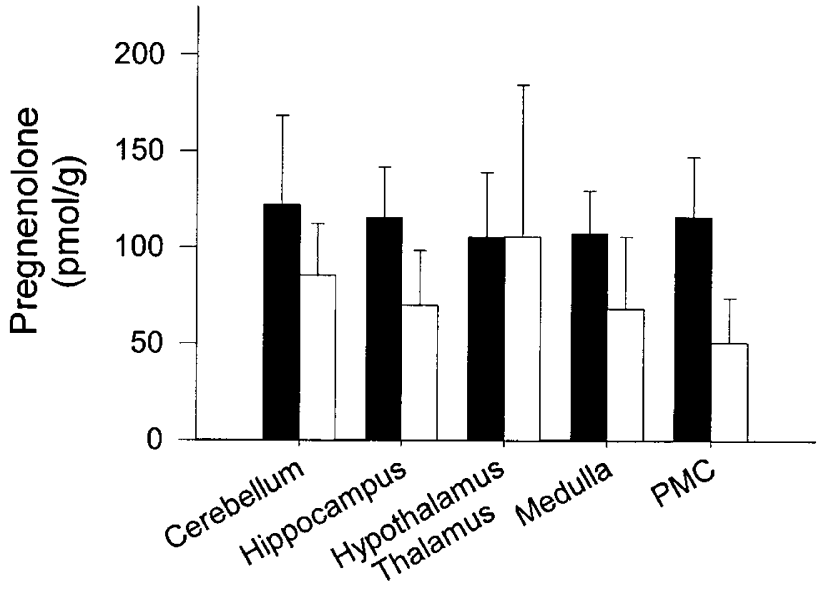

Figure 3. Content of $(A) \mathrm{AP},(B)$ progesterone, and $(C)$ pregnenolone in the cerebellum, hippocampus, hypothalamus/thalamus, medulla, and PMC of control fetuses at 132-134 d gestation ( $n=7$, filled columns) and umbilicoplacental embolized fetuses ( $n=5$, open columns) at 131-137 d gestation. Each bar represents the mean \pm SEM. Asterisks indicate significant difference between control and embolized fetuses $(p<0.05)$.

normal gestational AP concentrations during periods when adverse condition reduces the activity of the enzymes.

In contrast to brain content, plasma AP concentrations were markedly increased in the embolized fetuses. Interestingly, these findings indicate that plasma concentrations do not directly relate to brain content after the stress of embolization. This is consistent with our previous findings in sheep (38) and
A

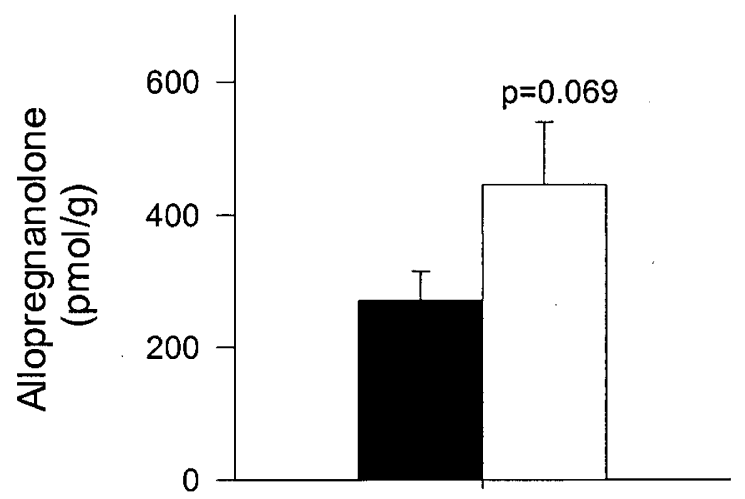

B

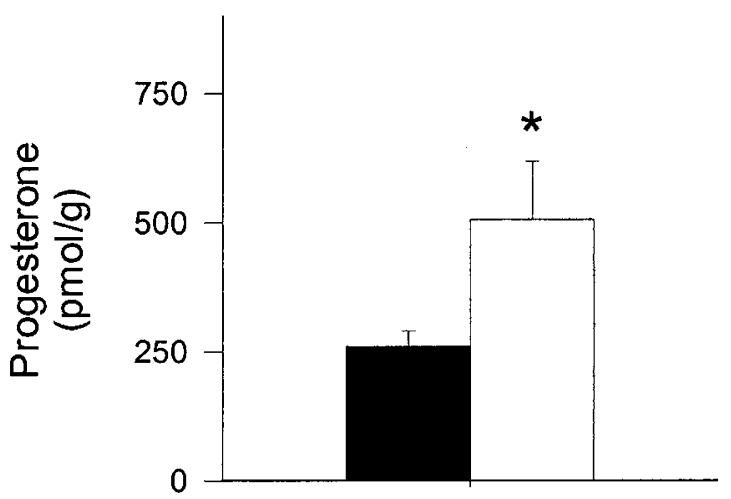

C

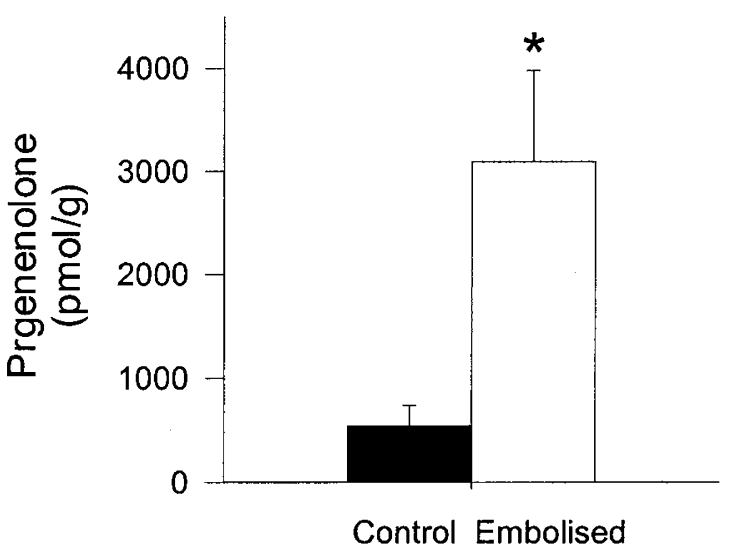

Figure 4. Adrenal gland content of $(A) \mathrm{AP},(B)$ progesterone, and $(C)$ pregnenolone of control fetuses at $132-134 \mathrm{~d}$ gestation $(n=7$, black columns) and umbilicoplacental embolized fetuses ( $n=5$, open columns) at 131-137 d gestation. Each bar represents the mean \pm SEM. Asterisks indicate significant differences between control and embolized fetuses $(p<0.05)$. Progesterone and pregnenolone content of the adrenal gland were both significantly increased $(p<0.05)$ with umbilicoplacental embolization.

of others in rats (11) that brain neurosteroid concentration is independent of, and is markedly higher than, plasma concentrations. The observation that adrenal progesterone and pregnenolone content were increased and AP content tended to be higher in the embolized fetuses suggests the rise in plasma levels may result from increased adrenal production. However, the present findings suggest that adrenal activation caused by a stress does not lead to increased AP concentrations in the brain.

Neurosteroids, including AP, have been shown to have neuroprotective functions (39), by modulation of the $\mathrm{GABA}_{\mathrm{A}}$ 

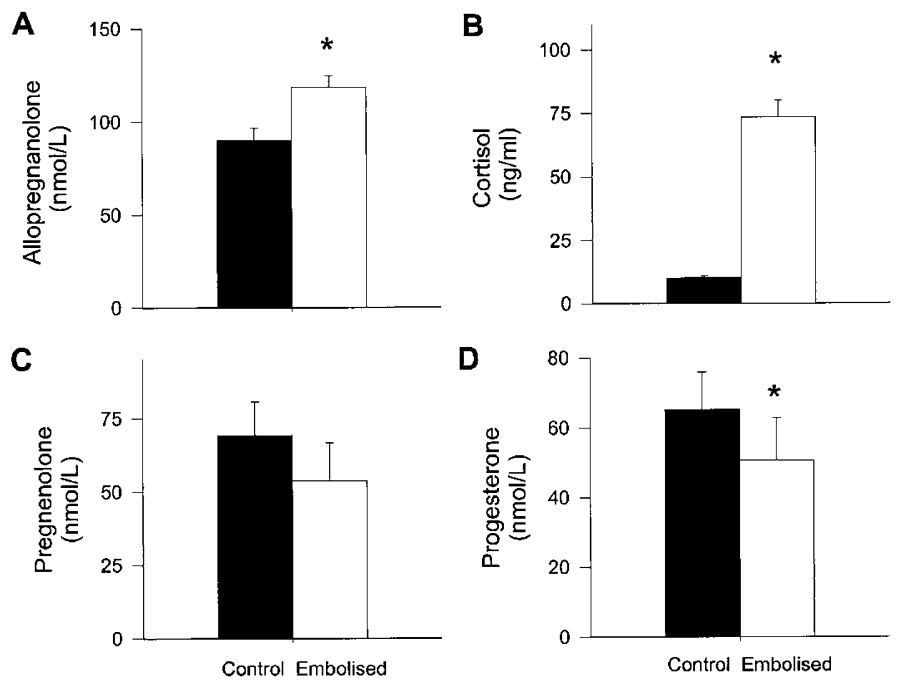

Figure 5. Plasma concentrations of $(A) \mathrm{AP},(B)$ cortisol, $(C)$ pregnenolone, and $(D)$ progesterone of control fetuses at $132-134 \mathrm{~d}$ gestation $(n=7$, filled columns) and umbilicoplacental embolized fetuses ( $n=5$, open columns) at 131-137 d gestation. Each bar represents the mean \pm SEM. Asterisks indicate significant differences between control and embolized fetuses $(p<0.05)$. Plasma progesterone and pregnenolone concentrations did not change, whereas cortisol and AP concentrations were significantly increased after umbilicoplacental embolization $(p<0.05)$.

receptor, particularly in the hippocampus. AP exerts a potent neuroprotective effect in cell viability studies with rat hippocampal slices and in primary hippocampal cultures as a result of the attenuation of glutamate-induced increases of intracellular calcium (40). GABA $\mathrm{A}$ receptor density has been shown to increase in the fetal brain between 85 and $128 \mathrm{~d}$ gestation such that adult concentrations are attained by $128 \mathrm{~d}$. These receptors are highly sensitive to AP, with concentrations of $50-150 \mathrm{nmol} / \mathrm{L}$ causing marked stimulation (41). Additionally, increases in progesterone and AP during pregnancy or after transient stress have been shown to decrease the expression of the $\mathrm{GABA}_{\mathrm{A}}$ receptor $\alpha 4$ subunit, resulting in a further enhancement of $\mathrm{GABA}_{\mathrm{A}}$ receptor steroid sensitivity (42-44) and the possible potentiation of AP action. Therefore, continuous stimulation of the $\mathrm{GABA}_{\mathrm{A}}$ receptor in the brain by $\mathrm{AP}$ and the possible down-regulation of the $\mathrm{GABA}_{\mathrm{A}} \alpha 4$ subunit may suppress fetal CNS activity in pregnancy, particularly during adverse conditions caused by a chronic reduction of placental function. The observed increase in both P450scc and $5 \alpha$ RII content may be a compensatory response that enables AP levels to be maintained despite a fall in neurosteroid precursor availability. This would preserve GABAergic inhibition that may be an intrinsic protective mechanism that counteracts the increased risk of hypoxia-induced excitotoxic injury.

Chronic fetal hypoxemia and altered endocrine status associated with intrauterine stresses and placental insufficiency (1) lead to the increased risk of permanent neurologic disability in the neonate (2). In utero insults have been shown to alter brain structure and composition, with changes in glial and neuron numbers (33-36). The present findings have shown that there is increased expression of $5 \alpha \mathrm{RII}$ in all areas of the brain and $\mathrm{P} 450 \mathrm{scc}$ in some areas, without a marked change in brain AP concentration. We speculate that these changes to the fetal brain may be an adaptation or a compensatory response, brought about through as yet unknown mechanisms, that act to maintain the AP concentrations and the level of GABAergic inhibitory activity, and thus to protect the fetal brain from excitotoxic injury.

Acknowledgments. We thank Alex Satragna for expert surgical assistance and Kylie Scott for technical assistance.

\section{REFERENCES}

1. Gagnon R, Challis J, Johnston L, Fraher L 1994 Fetal endocrine responses to chronic placental embolization in the late-gestation ovine fetus. Am J Obstet Gynecol 170:929-938

2. Marsal K, Ley D 1992 Intrauterine blood flow and postnatal neurological development in growth-retarded fetuses. Biol Neonate 62:258-264

3. Wieland S, Lan NC, Mirasedeghi S, Gee KW 1991 Anxiolytic activity of the progesterone metabolite 5 alpha-pregnan-3 alpha-o1-20-one. Brain Res 565:263-268

4. Crawley JN, Glowa JR, Majewska MD, Paul SM 1986 Anxiolytic activity of an endogenous adrenal steroid. Brain Res 398:382-385

5. Belelli D, Bolger MB, Gee KW 1989 Anticonvulsant profile of the progesterone metabolite 5 alpha-pregnan-3 alpha-ol-20-one. Eur J Pharmacol 166:325-329

6. Devaud LL, Purdy RH, Morrow AL 1995 The neurosteroid, 3 alpha-hydroxy-5 alpha-pregnan-20-one, protects against bicuculline-induced seizures during ethanol withdrawal in rats. Alcohol Clin Exp Res 19:350-355

7. Celotti F, Melcangi RC, Martini L 1992 The 5 alpha-reductase in the brain: molecular aspects and relation to brain function. Front Neuroendocrinol 13:163-215

8. Nicol MB, Hirst JJ, Walker D, Thorburn GD 1997 Effect of alteration of maternal plasma progesterone concentrations on fetal behavioural state during late gestation. $\mathrm{J}$ Endocrinol 152:379-386

9. Nicol MB, Hirst JJ, Walker DW 2001 Effect of finasteride on behavioural arousal and somatosensory evoked potentials in fetal sheep. Neurosci Lett 306:13-16

10. Barbaccia ML, Roscetti G, Trabucchi M, Cuccheddu T, Concas A, Biggio G 1994 Neurosteroids in the brain of handling-habituated and naive rats: effect of $\mathrm{CO} 2$ inhalation. Eur J Pharmacol 261:317-320

11. Purdy RH, Morrow AL, Moore Jr PH, Paul SM 1991 Stress-induced elevations of gamma-aminobutyric acid type A receptor- active steroids in the rat brain. Proc Natl Acad Sci U S A 88:4553-4557

12. Baulieu EE 1997 Neurosteroids: of the nervous system, by the nervous system, for the nervous system. Recent Prog Horm Res 52:1-32

13. Paul SM, Purdy RH 1992 Neuroactive steroids. FASEB J 6:2311-2322

14. Compagnone NA, Mellon SH 2000 Neurosteroids: biosynthesis and function of these novel neuromodulators. Front Neuroendocrinol 21:1-56

15. Steckelbroeck S, Watzka M, Reichelt R, Hans VH, Stoffel-Wagner B, Heidrich DD, Schramm J, Bidlingmaier F, Klingmuller D 2001 Characterization of the 5alphareductase-3alpha-hydroxysteroid dehydrogenase complex in the human brain. J Clin Endocrinol Metab 86:1324-1331

16. Fraser M, Braems GA, Challis JR 2001 Developmental regulation of corticotrophin receptor gene expression in the adrenal gland of the ovine fetus and newborn lamb: effects of hypoxia during late pregnancy. J Endocrinol 169:1-10

17. Cock ML, Harding R 1997 Renal and amniotic fluid responses to umbilicoplacental embolization for 20 days in fetal sheep. Am J Physiol 273:R1094-R1102

18. Scott JE, Grigsby PL, Hirst JJ, Jenkin G 2001 Inhibition of prostaglandin synthesis and its effect on uterine activity during established premature labor in sheep. J Soc Gynecol Investig 8:266-276

19. Andersson S, Russell DW 1990 Structural and biochemical properties of cloned and expressed human and rat steroid 5 alpha-reductases. Proc Natl Acad Sci U S A $87: 3640-3644$

20. Harlow E, Lane D 1988 Antibodies, A Laboratory Manual. Cold Spring Harbor Laboratory Press, Cold Spring Harbor, NY

21. Nguyen PN, Billiards SS, Walker DW, Hirst JJ 2003 Changes in 5alpha-pregnane steroids and neurosteroidogenic enzyme expression in the perinatal sheep. Pediatr Res 53:956-964

22. Aumuller G, Eicheler W, Renneberg H, Adermann K, Vilja P, Forssmann WG 1996 Immunocytochemical evidence for differential subcellular localization of 5 alphareductase isoenzymes in human tissues. Acta Anat 156:241-252

23. Bradford MM 1976 A rapid and sensitive method for the quantitation of microgram quantities of protein utilizing the principle of protein-dye binding. Anal Biochem 72:248-254

24. Barbaccia ML, Roscetti G, Trabucchi M, Ambrosio C, Massotti M 1992 Cyclic AMP-dependent increase of steroidogenesis in brain cortical minces. Eur J Pharmacol 219:485-486

25. Bernardi F, Salvestroni C, Casarosa E, Nappi RE, Lanzone A, Luisi S, Purdy RH, Petraglia F, Genazzani AR 1998 Aging is associated with changes in allopregnanolone concentrations in brain, endocrine glands and serum in male rats. Eur $J$ Endocrinol 138:316-321

26. Rice GE, Thorburn GD 1986 Characterization of particle-associated choriomammotrophin and progesterone in ovine placentomes. J Endocrinol 111:217-223

27. Bocking AD, Harding R 1986 Effects of reduced uterine blood flow on electrocortical activity, breathing, and skeletal muscle activity in fetal sheep. Am J Obstet Gynecol 154:655-662 
28. Ludbrook J 1998 Multiple comparison procedures updated. Clin Exp Pharmacol Physiol 25:1032-1037

29. Sadiq HF, Das UG, Tracy TF, Devaskar SU 1999 Intra-uterine growth restriction differentially regulates perinatal brain and skeletal muscle glucose transporters. Brain Res 823:96-103

30. Mallard C, Loeliger M, Copolov D, Rees S 2000 Reduced number of neurons in the hippocampus and the cerebellum in the postnatal guinea-pig following intrauterine growth-restriction. Neuroscience 100:327-333

31. Petratos S, Hirst JJ, Mendis S, Anikijenko P, Walker DW 2000 Localization of $\mathrm{P} 450$ scc and 5alpha-reductase type-2 in the cerebellum of fetal and newborn sheep. Brain Res Dev Brain Res 123:81-86

32. Matsui D, Sakari M, Sato T, Murayama A, Takada I, Kim M, Takeyama K, Kato S 2002 Transcriptional regulation of the mouse steroid 5alpha-reductase type II gene by progesterone in brain. Nucleic Acids Res 30:1387-1393

33. Rees S, Breen S, Loeliger M, McCrabb G, Harding R 1999 Hypoxemia nea mid-gestation has long-term effects on fetal brain development. J Neuropathol Exp Neurol 58:932-945

34. Penning DH, Grafe MR, Hammond R, Matsuda Y, Patrick J, Richardson B 1994 Neuropathology of the near-term and midgestation ovine fetal brain after sustained in utero hypoxemia. Am J Obstet Gynecol 170:1425-1432

35. Chanez C, Privat A, Flexor MA, Drian MJ 1985 Effect of intrauterine growth retardation on developmental changes in DNA and [14C]thymidine metabolism in different regions of rat brain: histological and biochemical correlations. Brain Res 353:283-292

36. Nitsos I, Rees S 1990 The effects of intrauterine growth retardation on the development of neuroglia in fetal guinea pigs. An immunohistochemical and an ultrastructural study. Int J Dev Neurosci 8:233-244
37. Seamark RF, Nancarrow CD, Gardiner J 1970 Progesterone metabolism in ovine blood: the formation of 3 alpha-hydroxy-pregn-4-en-20-one and other substances. Steroids 15:589-604

38. Billiards SS, Walker DW, Canny BJ, Hirst JJ 2002 Endotoxin increases sleep and brain allopregnanolone concentrations in newborn lambs. Pediatr Res 52:892-899

39. Majewska MD, Harrison NL, Schwartz RD, Barker JL, Paul SM 1986 Steroid hormone metabolites are barbiturate-like modulators of the GABA receptor. Science 232:1004-1007

40. Frank C, Sagratella S 2000 Neuroprotective effects of allopregnenolone on hippocampal irreversible neurotoxicity in vitro. Prog Neuropsychopharmacol Biol Psychiatry 24:1117-1126

41. Crossley KJ, Walker DW, Beart PM, Hirst JJ 2000 Characterisation of GABA(A) receptors in fetal, neonatal and adult ovine brain: region and age related changes and the effects of allopregnanolone. Neuropharmacology 39:1514-1522

42. Concas A, Follesa P, Barbaccia ML, Purdy RH, Biggio G 1999 Physiological modulation of $\mathrm{GABA}(\mathrm{A})$ receptor plasticity by progesterone metabolites. Eur J Phar macol 375:225-235

43. Concas A, Mostallino MC, Porcu P, Follesa P, Barbaccia ML, Trabucchi M, Purdy RH, Grisenti P, Biggio G 1998 Role of brain allopregnanolone in the plasticity of gamma-aminobutyric acid type A receptor in rat brain during pregnancy and after delivery. Proc Natl Acad Sci U S A 95:13284-13289

44. Smith SS 2002 Withdrawal properties of a neuroactive steroid: implications for GABA(A) receptor gene regulation in the brain and anxiety behavior. Steroids 67:519-528 